\title{
Acute emphysematous cholecystitis
}

\author{
A. McKibin \\ T. G. PARKS \\ M.B., F.R.C.S. \\ M.Ch., F.R.C.S.
}

Department of Surgery, Queen's University of Belfast

\section{Summary}

A case of acute emphysematous cholecystitis is described. In reviewing the literature the clinical features, pathogenesis and treatment of this condition are discussed.

\section{Introduction}

Acute emphysematous cholecystitis is a rare condition caused by gas-forming organisms and characterized radiologically by the presence of gas in the lumen or wall of the gall bladder. This clinical entity has been reported in the medical literature under such names as gas in the gall bladder, gas gangrene of the gall bladder, gaseous cholecystitis, pyopneumocholecystitis, pneumocholecystitis, gas phlegmon of the gall bladder, cholecystitis emphysematosa and gangrenous cholecystitis. Emphysematous cholecystitis is the terminology most commonly used.

\section{Case report}

A male patient, aged 61 years, was admitted as an emergency on 5 December 1972, with a 3-day history of right sided abdominal pain. The onset of the pain was gradual but it steadily increased in severit.. It did not radiate to the back or to the shoulder. The patient had vomited on two occasions but his appetite had remained reasonably normal until the day of admission. He had no previous history of abdominal symptoms or any other illness.

\section{Examination}

The patient was flushed and had a rather toxic appearance. He had a temperature of $100^{\circ} \mathrm{F}$, a pulse rate of $116 / \mathrm{min}$ and a BP of $130 / 90$. On abdominal examination a tender mass was palpable in the right hypochondrium. There was considerable guarding in this region. Bowel sounds were present but were diminished. Rectal examination revealed no abnormality.

\section{Investigations}

Haemoglobin was $14.8 \mathrm{gm} / 100 \mathrm{ml}$ and white blood-cell count was $12,400 /$ cc. Electrolytes were normal but blood urea was $55 \mathrm{mg} / 100 \mathrm{ml}$. Straight $\mathrm{X}$-ray of his abdomen (Fig. 1) showed elevation of

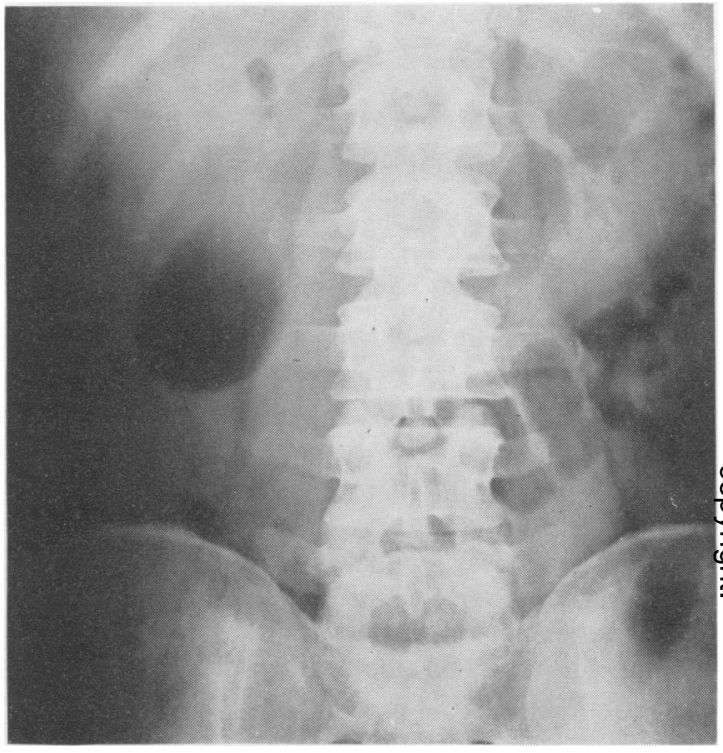

FIg. 1. Straight X-ray of abdomen showing gaseous distension of gall bladder.

the right hemidiaphragm; a gas-filled viscus corresponding in shape and position to the gall bladder was noted and on the erect film a fluid level was seen in this area (Fig. 2).

A provisional diagnosis of acute cholecystitis due to gas-forming organisms was made.

\section{Treatment}

Treatment with intravenous fluids and Ampicillin was commenced. Within $2 \mathrm{hr}$ of admission the patient was obviously more toxic with a pulse rate of $130 / \mathrm{min}$ and a temperature of $102^{\circ} \mathrm{F}$. Immediate laparotomy was therefore decided upon because of these findings, and the large amount of gas demonstrated radiologically. The gall bladder was found to be tensely distended and there were numerous gangrenous areas in the wall. There was considerable oedema of the pericholecystic tissues but few adhesions. A routine cholecystectomy was carried out. 


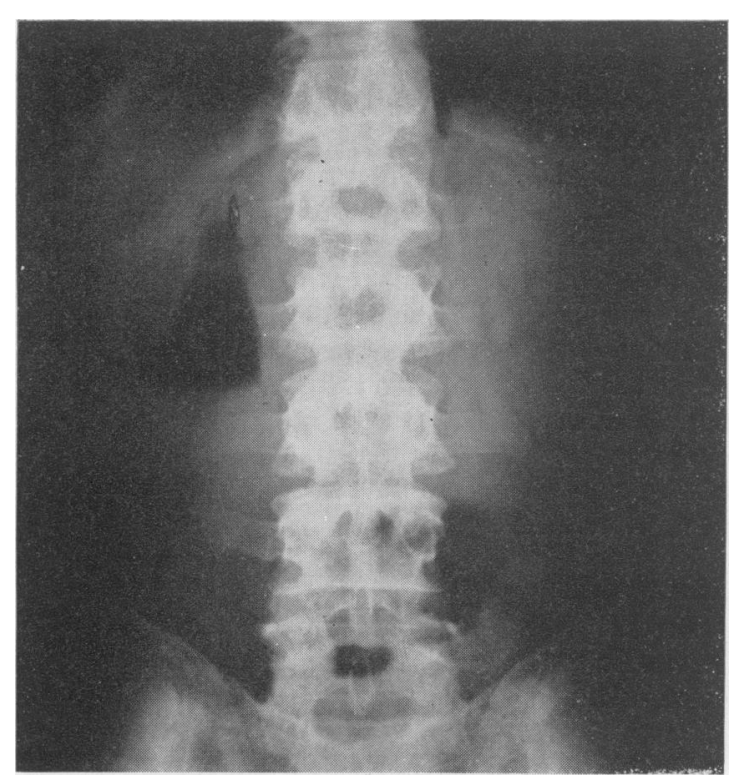

FIG. 2. Erect X-ray of abdomen demonstrating fluid level in gall bladder.

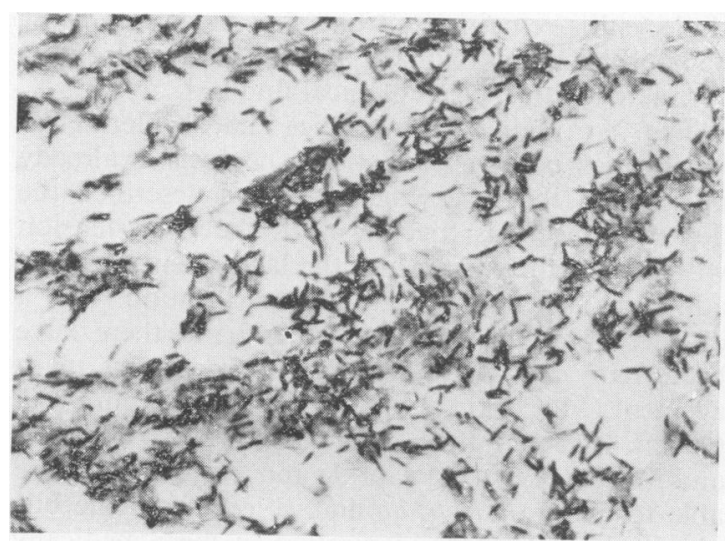

FIG. 3. Photomicrograph of gall bladder wall showing heavy infiltration with Gram positive bacilli $(\times 600)$.

His post-operative course was uneventful and he was discharged 10 days after operation.

\section{Pathology}

On opening the gall bladder it was found to contain a considerable amount of gas, watery haemorrhagic bile and multiple small mixed gall stones, one of which was impacted in the cystic duct. The entire wall of the gall bladder was oedematous and the serous surface was deeply injected and partially covered with fibrin. There was diffuse ulceration of the mucosa and blackish discolouration.

Histologically, multiple areas showed complete necrosis of all coats and heavy infiltration by acute inflammatory cells. Blood vessels were involved in the necrosis but there was no evidence of preexisting arterial disease. Brown's stain revealed large numbers of Gram positive bacilli in the necrotic mucosa (Fig. 3). Culture of the gall bladder contents revealed a profuse growth of toxin-producing Clostridium welchii.

\section{Discussion}

Stolz in 1901 reported the incidental finding of gas in the gall bladder and biliary ducts in three autopsies but felt that the presence of this gas was a post mortem development. Pende (1907) and Lobingier (1908) described the finding of gas in the bladder at operation. The earliest records of preoperative radiological diagnoses were those of Von Friederich (1929) and Hegner (1931). The increasing use of the plain X-ray film for diagnosis of the acute abdomen has contributed to the more frequent recognition of this entity. About 120 cases of emphysematous cholecystitis have now been reported in the world literature.

\section{Clinical features}

The clinical picture of this condition is that of an ordinary acute cholecystitis, but there may be several atypical features. The patient is generally more ill and toxic than the clinical and laboratory findings would suggest (Wilson, 1958). This variety of cholecystitis has a male preponderance and is seen three to seven times more frequently in men than in women (May and Strong, 1971). Although the condition may occur in young adults, the youngest recorded being 16 years of age, most patients are in the older age brackets, with an average age of about 62 years (Berk and Monroe, 1965). Twenty to $30 \%$ of cases have been found to suffer from diabetes mellitus (Edinburg and Geffen, 1958; Marshall and Hartzog, 1964). In a collected group of seventy-three cases a mass was palpable at some stage in almost half and jaundice was present in about a quarter of the patients (Bigler, 1960). Over half of the patients have pyrexia in the range $100-102^{\circ} \mathrm{F}$, and over $90 \%$ of cases develop a considerable leucocytosis.

The diagnosis of acute emphysematous cholecystitis rests on the clinical manifestations of acute cholecystitis together with characteristic radiological findings. Gas may be demonstrable in the gall bladder on straight $\mathrm{X}$-ray of abdomen within $24-48 \mathrm{hr}$ of onset of symptoms (McCorkle and Fong, 1942; Gowdy and Copeland, 1950; Ryan, Harrigan and Penny, 1952). Initially the gas may produce a radiolucent layer in the wall of the gall bladder, but on other occasions gas is first demonstrable in the lumen of the gall bladder. As illustrated 
by the present case, a gas-fluid level may be seen in a film taken with the patient erect. At a later stage, gas tends to penetrate into the pericholecystic tissues to appear as numerous radiolucent striae. The biliary tree is rarely outlined by gas (McCorkle and Fong, 1942; Culver and Kline, 1948). Boerema and McWilliam (1970) described a case of emphysematous cholecystitis in which the only radiological abnormality was evidence of free gas under the diaphragm. When gas is seen only in the lumen of the gall bladder, another source of the gas in the biliary system such as spontaneous biliary enteric fistula or previous cholecystenterostomy must be excluded. A further differential diagnosis of emphysematous cholecystitis is gas in a high retrocaecal appendix abscess. The condition must also be distinguished from local meteorism of adjacent gut, which may be associated with acute cholecystitis. Incompetence of the sphincter of Oddi may cause confusion but signs of acute cholecystitis will be absent and reflux may be demonstrable on barium meal. Lipomas of the gall bladder can cause a ring shadow, but are extremely rare.

\section{Pathogenesis}

The initiating mechanism appears to be some obstruction at the junction of the gall bladder and cystic duct (Hutchinson, 1946; Gowdy and Copeland, 1950; Heifetz, 1956). This is usually due to a stone, but may also be caused by angulation, kinks, anomalous blood vessels, adhesions, enlarged lymph nodes or tumours. The local oedema at the outlet and the stretching of the wall lead to impairment of vascular supply to the gall bladder. The resultant ischaemic tissue provides fertile soil for multiplication of gas forming organisms which are not infrequently found in this are in both normal and disease states (Gordon-Taylor and Whitby, 1930; Andrews and Henry, 1935; Schottenfeld, 1950). Reduction in the concentration of bile salts which accompanies the acute inflammatory changes also enhances bacterial growth in the bile and the gall bladder wall (Ravdin et al., 1934). Inflation experiments by Heifetz and Rifkin (1962) on excized gall bladders demonstrated that when distention of the gall bladder becomes excessive, leakage through the mucosa occurs where the muscle layer is deficient, i.e. in the cystic duct area. There is a tendency for the gas to spread from this region towards the fundus in the perimuscular layers finally rupturing through the serosa into the peritoneal cavity. According to McCorkle and Fong's (1942) report the gas may disappear within 12 days but in one patient it persisted $3 \frac{1}{2}$ months.

A wide variety of organisms have been recovered in reported cases of emphysematous cholecystitis, but at least $50 \%$ of cultures revealed a growth of one of the Clostridia (Bigler, 1960). Escherichia coli, Proteus vulgaris, Aerobacter aerogenes, non-haemolytic Streptococcus, Staphylococcus and Klebsiella have also been found.

May and Strong (1961) produced evidence to show that acute emphysematous cholecystitis may be the result of a primary vascular occlusion of the cystic artery or its branches; this might explain the increased incidence in males and diabetics, both of whom are more prone to vascular disease. In our patient the blood vessels in the gall bladder wall were histologically normal. On the other hand, there was definite obstruction of the cystic duct due to impaction of a gall stone resulting in marked distention of the gall bladder.

\section{Management}

As in any severe cholecystitis a broad spectrum antibiotic, usually a tetracycline or Ampicillin, intravenous fluids and if necessary naso-gastric aspiration are used.

The value of either polyvalent gas gangrene antitoxin or hyperbaric oxygen therapy is difficult to assess.

The role of surgery in acute emphysematous cholecystitis remains controversial. Each case must be approached individually and the clinical progress correlated with the radiological findings.

The X-ray diagnosis implies that bacterial infection has occurred and tissue necrosis is already present. In the case which we have described the degree of necrosis together with the great tension within the gall bladder and the lack of surrounding adhesions suggested that free perforation was a distinct possibility. On the other hand there have been many reports of successful conservative management (McCorkle and Fong, 1942; Edinburg and Geffen, 1958; De Jode, 1960; Parsons, 1963; Rosoff and Meyers, 1966). McCorkle and Fong (1942) were able to culture Clostridia and $E$. coli from the bile obtained on duodenal aspiration in these medically managed patients. In view of the risk of disrupting and disseminating a more localized gas-bacillus infection by operative manipulations, these authors suggested that a conservative approach 'should be pursued even more persistently than usual'. They also suggested that early interval surgery should be avoided. However, we would agree with the policy advocated by Berk and Monroe (1965), namely, that if the patient's condition can be improved, and there are no compelling reasons not to operate, surgical intervention with a view toward cholecystectomy is advisable. Schein (1972) advises emergency surgery if the patient is diabetic, and elective surgery if he is not a diabetic. However, with evidence of spreading peritonitis, surgical intervention is indicated.

This condition has been associated with a high 
overall mortality, of the order of $10-25 \%$ in several collected series (Bigler, 1960; Marshall and Hartzog, 1964; Sarmiento, 1966). More frequent early surgical intervention with antibiotic cover might conceivably lead to a reduction in this figure.

\section{Acknowledgment}

We wish to thank Professor F. McKeown, Pathology Department, Queen's University of Belfast for her detailed pathological examination of the gall bladder.

\section{References}

ANDREWS, E. \& HenRY, L.D. (1935) Bacteriology of normal and diseased gallbladders. Archives of Internal Medicine, 56, 1171.

BERK, J.E. \& MONROE, L.S. (1965) In: Gastroenterology, 2nd edition. (Ed. by H. L. Bockus). W. B. Saunders Co., Philadelphia and London.

Bigler, F.C. (1960) Acute gaseous cholecystitis. American Journal of Medicine, 29, 181.

BOeRema, W.J. \& McWilliams, R.A. (1970) Emphysematous cholecystitis: an unusual form of presentation. Australian and New Zealand Journal of Surgery, 39, 258.

Culver, G.J. \& KLINE, J.R. (1948) Acute gaseous cholecystitis: report of a case. Radiology, 50, 536.

DE JODE, L.R. (1960) Total necrosis of gall bladder after emphysematous cholecystitis: recovery. British Medical Journal, 2, 1855.

EdinburG, A. \& Giffen, A. (1958) Acute emphysematous cholecystitis. American Journal of Surgery, 96, 66.

GoRdon-TAYloR, G. \& WhITBY, L.E.H. (1930) Bacteriological study of fifty cases of cholecystectomy with special reference to anaerobic infection. British Journal of Surgery, $18,178$.

Gowdy, J.F. \& Copeland, N.N. (1950) Acute gaseous cholecystitis. New England Journal of Medicine, 242, 647.

Hegner, C.F. (1931) Gaseous pericholecystitis. American Journal of Surgery, 22, 993.
Heifetz, C.F. \& Rifkin, S.M. (1961) Acute pneumocholecystitis. Journal of Abdominal Surgery, 3, 75.

Hutchinson, W.R.S. (1946) Gas gangrene of gall bladder. British Medical Journal, 1, 915.

LOBINGIER, A.S. (1908) Gangrene of the gall bladder. Annals of Surgery, 48, 72.

Marshall, J.F. \& Hartzog. D.C. (1964) Acute emphysematous cholecystitis. Annals of Surgery, 159, 1011.

MaY, R.E. \& Strong, R. (1971) Acute emphysematous cholecystitis. British Journal of Surgery, 58, 453.

MCCORKLE, H. \& FoNG, E.E. (1942) The clinical significance of gas in the gall bladder. Surgery, 11, 851.

Parsons, L. Jr (1963) Pneumocholecystitis. American Journal of Surgery, 106, 544.

Pende, N. (1907) La piopneumocolecestite (studio clinico et batterilogico). Bollietino de Societa Lancisiana de ospital di Roma, 27, 82.

Ravdin, I.S., Riegel, C., Johnston, C.G. \& Morrison, P.J. (1934) Studies in biliary tract disease. Journal of American Medical Association, 103, 1504.

Rosoff, L. \& MeYers, H. (1966) Acute emphysematous cholecystitis. American Journal of Surgery, 111, 410.

Ryan, E.A., Harrigan, E. \& Penny, S.F. (1953) Acute gaseous cholecystitis. Canadian Medical Association Journal, 69, 606.

SARmiento, R.V. (1966) Emphysematous cholecystitis. Archives of Surgery, 93, 1009.

Schein, C.F. (1972) Acute Cholecystitis. Harper and Row, New York.

SchotTenfeLd, L.E. (1950) Anaerobic infection of the biliary tract. Surgery, 27, 701.

Stolz, A. (1901) Uber gasbildung in den gallenwagen. Virchow's Archives of Pathological Anatomy, 165, 90.

Von Friederich, cited by Culver, C.J. \& Kline, J.R. (1948) Acute gaseous cholecystitis. Report of case. Radiology, 50, 536.

Wilson, W.A. (1958) Acute cholecystitis due to gas producing organisms. British Journal of Surgery, 45, 333.

\title{
Lipomatous pseudohypertrophy of the pancreas associated with chronic pulmonary suppuration in an adult
}

\author{
D. I. M. SIEGLER* \\ M.B., M.R.C.P.
}

Medical Registrar, The Brompton Hospital, London, S.W.3.

\section{Summary}

This report describes a man who died at the age of $\mathbf{4 3}$ of overwhelming pulmonary suppuration in association with pancreatic steatorrhoea. Autopsy revealed lipomatous pseudohypertrophy of the pancreas. The patient is the longest documented survivor with pulmonary complications of lipomatous pseudohypertrophy of the pancreas. The literature on this rare condition is reviewed.

*Present address: Senior Medical Registrar, Royal Free Hospital, London, N.W.3.

\section{Case report}

A 42-year-old insurance broker was first seen at the Brompton Hospital in July 1971. At the age of 8 investigations into recurrent lower respiratory tract infections had revealed a collapsed left lower lobe and a haemoglobin concentration of $8.6 \mathrm{~g} / 100 \mathrm{ml}$. He received postural drainage and remained healthy during his school years. In his early 'teens he received a course of deep X-ray therapy for a low back pain with complete and permanent relief of symptoms. At the age of 20 , he was discharged from 